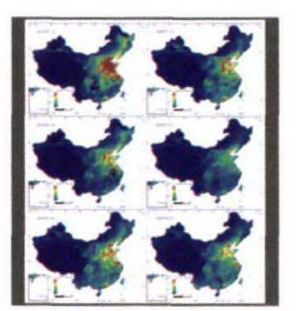

\author{
封面说明 \\ About the Cover \\ 新冠疫情期间中国地区大气二氧化氮浓度遥感监测 \\ Satellite observations of $\mathrm{NO}_{2}$ over China during the period of COVID-19
}

封面图片为搭载于美国 Aura 卫星上的 OMI 载荷监测的中国地区 2020 年 1 月、2 月及 2019 年同期大气二氧化氮对流层柱浓度月均值分布图。卫星监 测结果表明 2020 年 2 月二氧化氮对流层浓度和工业热源企业耗能水平较同期均呈现显著下降趋势。在新型冠状病毒疫情得到基本控制之后，中国大部 分地区的工业热源企业虽已逐步有序地恢复生产，但复工区域仍处于低能耗水平，生产规模尚未完全恢复。利用卫星遥感技术监测来源于工业高温燃烧 以及机动车尾气的大气二氧化氮浓度变化及工业热源企业热排放变化，提供了一种新的视角反映工业活动与人们出行状态。相关研究结果详见第 7 期第 824-836 页 "新型冠状病毒疫情期间复工复产卫星遥感监测" (审图号: GS (2020) 1848 号)。

The cover image shows the Aura/OMI monthly tropospheric $\mathrm{NO}_{2}$ Vertical Column Density (VCD) data over China during the periods from January to February in 2020 and 2019, respectively. Satellite observations indicate that there are significant reductions of both $\mathrm{NO}_{2}$ emission and industrial energy consumption in February 2020, compared to those of both January 2020 and February 2019. With the abatement of COVID-19 in China, although many industrial factories started to re-open, production capacities of most industries were limited, and were still not yet fully resumed. The satellite remote sensing technology can provide a new view to quantify the status of industrial activities and public travel,which monitors variations of the heat emission from heavy industrial sectors with high-energy consuming and the atmospheric $\mathrm{NO}_{2}$ mainly from industrial emissions and vehicles. For more details, please see the research progress "Satellite observations of the return-to-work over China during the period of COVID-19" in volume 24, issue 7 (page 824-836).

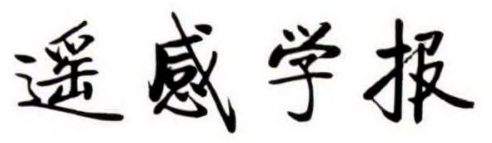

YAOGAN XUEBAO（月刊１997年创刊）

第24卷 第6期 2020年6月25日

\section{JOURNAL OF REMOTE SENSING}

(Monthly, Published since 1997)

Vol.24 No.6 June 25, 2020

\begin{tabular}{|c|c|c|c|c|}
\hline 管 & 中国科学院 & Superintended & by & Chinese Academy of Sciences \\
\hline 办 & $\begin{array}{l}\text { 中国科学院遥感与数字地球研究所 } \\
\text { 中国地理学会环境遥感分会 }\end{array}$ & Sponsored & by & $\begin{array}{l}\text { Institute of Remote Sensing and Digital Earth,CAS } \\
\text { The Associate on Environment Remote Sensing } \\
\text { of China }\end{array}$ \\
\hline 编 & 顾行发 & Editor in Chief & & GU Xingfa \\
\hline 辑 & $\begin{array}{l}\text { 《遥感学报》编委会 } \\
\text { 北京市海淀区北四环西路19号 } \\
\text { 由编 : } 100190 \text { 电话 : 86-10-58887052 } \\
\text { http://www.jors.cn } \\
\text { E-mail: jrs@radi.ac.cn }\end{array}$ & Edited & by & $\begin{array}{l}\text { Editorial Board of Journal of Remote Sensing } \\
\text { Add: P.O.Box 2702, Beijing 100190, China } \\
\text { Tel: 86-10-58887052 } \\
\text { http://www.jors.cn } \\
\text { E-mail: irs@radi.ac.cn }\end{array}$ \\
\hline $\begin{array}{l}\text { 出版 } \\
\text { 印刷装订 }\end{array}$ & $\begin{array}{l}\text { 料学出版 社 } \\
\text { 北京科信印刷有限公司 }\end{array}$ & $\begin{array}{l}\text { Published } \\
\text { Printed }\end{array}$ & $\begin{array}{l}\text { by } \\
\text { by }\end{array}$ & $\begin{array}{l}\text { Science Press } \\
\text { Beijing Kexin Printing Co. Ltd. }\end{array}$ \\
\hline 总 发 行 & $\begin{array}{l}\text { 科学出版和 } \\
\text { 北京东黄城根北街16号 国内邮发代号: 82-324 } \\
\text { 由政编码 : } 100717 \\
\text { 电话 : 86-10-64017032 } \\
\text { 淘宝店铺名称: 中科期刊 }\end{array}$ & Distributed & by & $\begin{array}{l}\text { Science Press } \\
\text { Add: } 16 \text { Donghuangchenggen North Street, } \\
\quad \text { Beijing } 100717 \text {, China } \\
\text { Tel: } 86-10-64017032 \\
\text { Taobao:Zhongke Journal }\end{array}$ \\
\hline 国外发行 & $\begin{array}{l}\text { 中国国际图书贸易总公司 } \\
\text { 北京 } 399 \text { 信箱 邮政编码 : } 100044 \text { 国外发行代号: BM } 1002\end{array}$ & Overseas distributed & by & $\begin{array}{l}\text { China International Book Trading Corporation } \\
\text { Add: P.O.Box 399, Beijing 100044, China }\end{array}$ \\
\hline
\end{tabular}

中国标准连续出版物号: ISSN 1007-4619

CODEN YXAUAB CN 11-3841/TP

eISSN 2095-9494

定价：70.00元

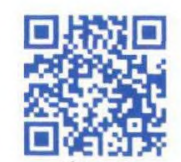

官网

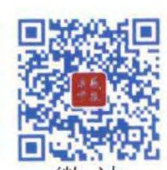

微站

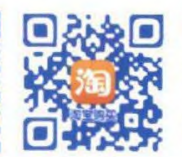

淘宝

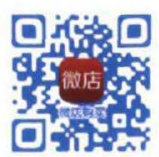

微店
I S SN 1007-4619

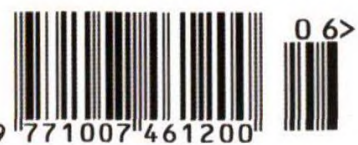

